- Friction with the upper atmosphere is steadily dragging on the orbiting spacecraft, now just over 200 kilometres above Earth at its lowest point. Zakharov says it is expected to fall in mid-December. Molczan, who has performed his own analysis of the orbital decay, says it could be as late as January.

Re-entry could make for a massive fireball, as most of the weight of the spacecraft is in its liquid fuel - much of it meant for a return trip from Mars. A statement on the Roscosmos website says that the craft will blow up in the heat of re-entry, which would reduce the risk of anything reaching the ground. But Jonathan McDowell, an astronomer and satellite watcher at the Harvard-Smithsonian Observatory in Cambridge, Massachusetts, says that it's also possible that the fuel, made up of hydrazine and dinitrogen tetroxide, will freeze in space during the spacecraft's initial descent, increasing the chance that some of the craft and its contents might survive the plunge. "Now you have a lump of a couple of tonnes of toxic sludge that's falling out of the sky," he says.

Even without the public-relations disaster of a crash to Earth, the damage to Russia's future planetary plans will be considerable. Zakharov says it will be difficult for Roscosmos to consider repeating the US\$163million Phobos mission. The agency and its primary contractor, Lavochkin, had also wanted to pur-

sue missions to the

Moon, Mars, Venus,

Mercury and even

Europa, the icy

moon of Jupiter. But

"The project was doomed from the beginning." the plans, never firm,

are now more uncertain. A 2014 launch of the Luna-Resource mission, a Moon lander paired with an Indian-built orbiter and rover, is still on track, Zakharov says. But after the loss of Phobos-Grunt, which carried a small Chinese satellite, India will be rightly concerned, says Sagdeev. "If something similar happens to the Indian payload, it would be a real disaster."

In the old days, failures could be tolerated, because the Soviet Union would launch mission after mission until each problem was fixed, says Louis Friedman, former director of the Planetary Society in Pasadena, California, and principal investigator of a small astrobiology experiment on Phobos-Grunt. But with no money for frequent launches, Roscosmos and Lavochkin - which has designed and built all Russia's interplanetary missions since the dawn of the space age - will have to change their cultures, Friedman says. "The hope is that there will be a real shake-up," he says. "Do I think that will happen? History says it won't." -

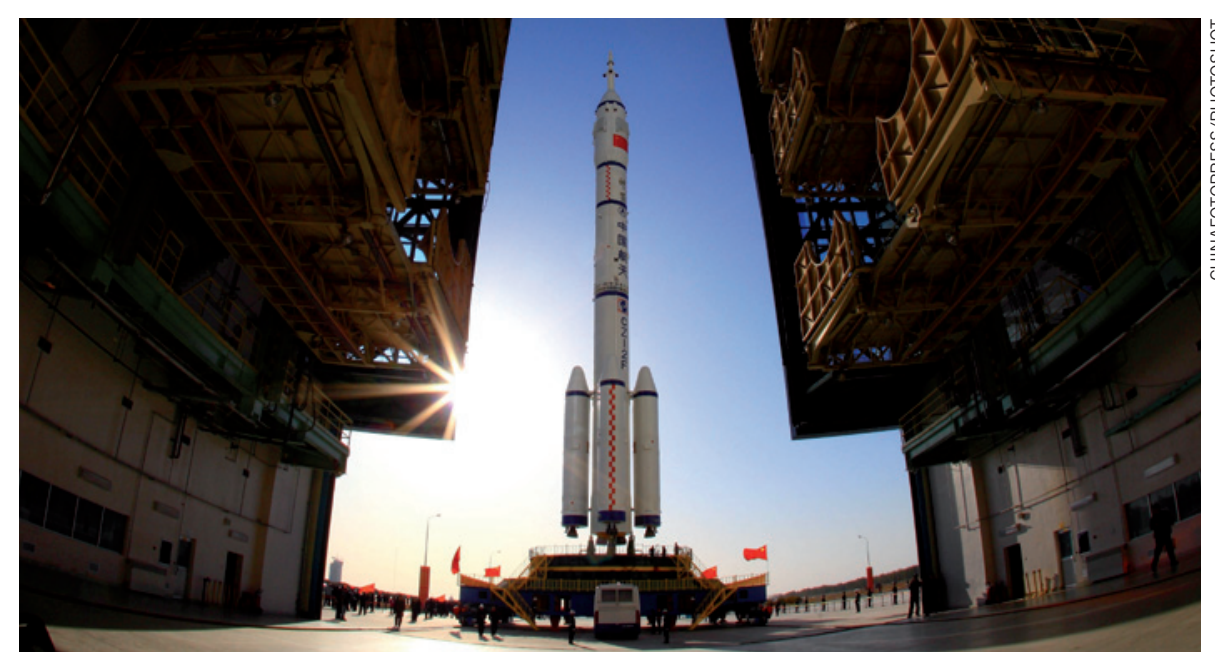

The Shenzhou-8 spacecraft (above, before launch) has docked successfully with the Tiangong-1 module.

SPACE EXPLORATION

\title{
China forges \\ ahead in space
}

\section{Mars-probe problems are a minor blip in a bold strategy.}

\section{BY DAVID CYRANOSKI}

$\mathrm{T}$ The likely demise of Russia's PhobosGrunt mission has dashed China's hopes for its first Mars orbiter, Yinghuo-1, which was piggybacking on the larger craft (see page 275). But it is a relatively small setback for a nation that has notched up a string of highprofile space successes in recent years, including this month's 'heavenly kiss' of two unmanned orbiters, Shenzhou-8 and Tiangong-1 - a milestone in the country's effort to build a manned space station, the Tiangong ('Heavenly Palace'), by the end of the decade.

And ambitious moves on the ground suggest that China will increasingly be able to develop and launch its probes without partnering with other nations. In July, the Chinese Academy of Sciences (CAS) in Beijing opened its National Space Science Center (NSSC), which will take charge of overall planning for the country's space science. "China was a space country without a space science programme," says Ji Wu, the centre's director. Now that the CAS "has got government support to manage space science missions as a series", he says, "it will lead to a new era for space science in China".

For years, the lack of a clear national strategic plan that prioritized missions has hampered researchers' efforts to launch space telescopes or planetary probes. The convoluted relationships between the various Chinese agencies involved in funding, building and launching satellites impeded many mission proposals, and decisions about their fate were at best "opaque", according to one European researcher who has collaborated with Chinese space scientists.

Centralized planning under the NSSC could change that. The centre already has about 450 staff, including 50 scientists, inherited from its predecessor, the Center for Space Science and Applied Research, which last year had a budget of 300 million renminbi (US\$47 million). (Individual missions have separate funding.) That will grow to 700 million renminbi as the centre develops space science missions over the next few years.

First in the queue is an orbiting X-ray observatory, HXMT, with a budget of about 900 million renminbi and due for launch in 2014. Then there is the KuaFu mission, which aims to reach space the following year, to study the Sun's effects "Intwe on space weather China will be dominating the United States."

Later missions could fly on China's Long March 5 rocket, expected to enter service in 2014 . Its ability

to loft payloads of 14 tonnes into a highly elliptical orbit should allow China to launch interplanetary missions as large as Phobos-Grunt.

The NSSC's mission selection and planning procedure is "more or less the way we prepare missions at ESA", says Philippe Escoubet, a mission manager at the European Space Agency's (ESA's) Science and Robotic 
Exploration Directorate in Noordwijk, the Netherlands. "It's very much welcome."

Escoubet collaborated with Chinese scientists on the Double Star mission, a joint effort with ESA that launched two satellites, in 2003 and 2004, to study Earth's magnetosphere. He believes that, as China devotes more resources to space science, there will be greater opportunities for collaboration.

CAS president Bai Chunli, in his speech at the NSSC inauguration, confirmed that the centre will endeavour to "deepen international cooperation", adding that "scientists from around the world will be able to access data" from the missions.

But $\mathrm{Wu}$ must win the confidence of potential collaborators who have been frustrated in the past by bureaucracy and delays when they tried to work with China. Indeed, several scientists interviewed by Nature for this article were unwilling to speak on the record, fearing that future partnerships with China could be jeopardized.

Some worry that the new missions, like China's space station, may be exclusively national projects. "In principle, it is relatively advantageous to European researchers to be involved in Chinese missions," says one UK space scientist. "However, there has not yet been a Chinese mission with an instrument selection process that was open to the wider world, as opposed to 'by invitation."

Collaboration with scientists in the United States is certainly unlikely. That country has always vetoed Chinese participation in the International Space Station, and congressional antipathy towards China was ramped up earlier this year. In April, congressman Frank Wolf (Republican, Virginia), who chairs the subcommittee that funds NASA, modified a spending bill to prevent the agency from using federal funds on joint projects with China. But if China's planned space science missions go ahead "and the United States is locked out, it will be a huge missed opportunity", says a US-based astrophysicist familiar with Chinese science.

"China is firmly committed to upping its profile in space science, both to expand its technological base and to boost its domestic and international prestige," says space security expert Clay Moltz of the Naval Postgraduate School in Monterey, California. "As long as China's economy continues to deliver strong growth, I expect space science missions will continue to expand."

A European scientist who has worked with China's space scientists agrees that its space science will flourish, particularly as Chinese senior scientists return from research positions in the West. "In twenty years, China will be dominating the United States," he says. "There is a sense of national urgency and dedication in China, and the rate at which they learn is phenomenal. It won't take that long." - SEE EDITORIAL P.267

ENVIRONMENT

\section{Gulf ecology hit by coastal development}

\section{Dubai's artificial islands are affecting marine ecosystems.}

\section{BY DANIEL CRESSEY}

$\mathrm{U}$ ntrammelled development, weak regulatory oversight and a lack of scientific monitoring are seriously threatening ecosystems along the coast of the Gulf, according to an extensive assessment of the region's marine environment.

Sea-front projects ranging from desalination plants to artificial islands in the gulf between the Arabian Peninsula and Iran have transformed the entire coastline in the past few decades. More than $40 \%$ of some countries' shores are now developed. The change is happening more quickly, and with greater environmental impact, than in any other coastal region. "Things are being put in place so quickly we don't know what is going to happen," says Peter Sale, a marine ecologist at the United Nations University (UNU) Institute for Water, Environment and Health in Hamilton, Ontario, Canada, who co-authored the report ${ }^{1}$.

The report synthesizes existing research with the UNU team's own assessments of the impact of projects such as Palm Jumeirah, an artificial archipelago more than 5 kilometres wide in Dubai in the United Arab Emirates. Some 94 million cubic metres of sediment were dredged up to make the islands. Sale says that such projects are "so substantial that they have changed $\rightarrow$ NATURE.COM Read more from the region at Nature Middle East: go.nature.com/9aofs6 ecology in ways that are only going to become clear in decades".

Water around some parts of the islands can remain almost stationary for several weeks, increasing the risk of algal blooms. And although fish have colonized the new environment, they are not all the same species that were there before.

The report says that legislation and regulatory frameworks are often inadequate to properly monitor such projects. Environmental assessments that could take a year in Western nations might be done far more superficially in ten weeks in the Gulf, for example. And a lack of scientific input to the development process means that there is often little or no environmental monitoring. "There is a clear deficit, not only in the capacity but in scientific knowledge, and a limited amount of scientific data on which to base decisions," says report co-author Hanneke Van Lavieren, a programme officer for coastal ecosystems at the UNU.

The problem is becoming increasingly urgent. The region has already lost $70 \%$ of its coral reefs since 2001, with most of the remaining reefs threatened or degraded, for example ${ }^{2}$. Construction of Dubai's Palm Jebel Ali, an even larger artificial archipelago, has already destroyed 8 square kilometres of natural reef, the report notes.

"All the ecological trajectories are downhill," says Charles Sheppard, an ecologist at the University of Warwick, UK, who has studied environmental change in the Gulf. "The prognosis isn't good unless there is major change."

1. Van Lavieren, $\mathrm{H}$. et al. Managing the Growing Impacts of Development on Fragile Coastal and Marine Ecosystems: Lessons from the Gulf (UNU, 2011).

2. Wilkinson, C. (ed.) Status of Coral Reefs of the World: 2008 (GCRMN, 2008).

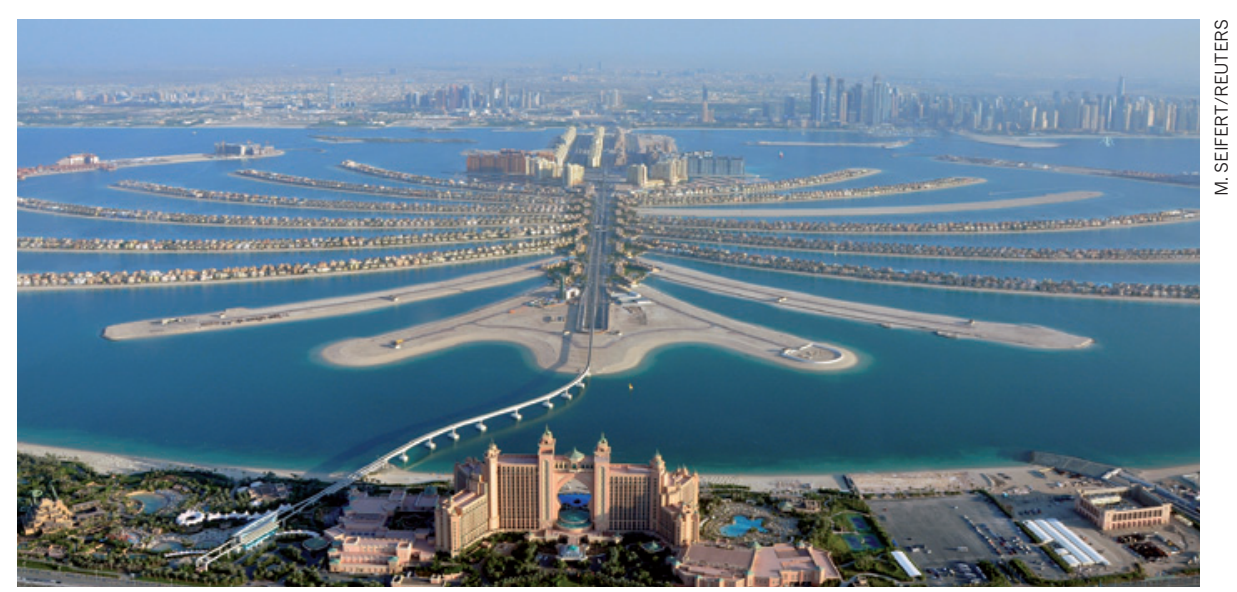

Problems are brewing in the still waters around the artificial Palm Jumeirah archipelago. 